\title{
Design of a randomised controlled trial on immune effects of acidic and neutral oligosaccharides in the nutrition of preterm infants:
} carrot study

\author{
Elisabeth AM Westerbeek ${ }^{1}$, Ruurd M van Elburg*1, Anemone van den Berg1, \\ Jolice van den Berg${ }^{1}$, Jos WR Twisk ${ }^{2}$, Willem PF Fetter ${ }^{1}$ and Harrie N Lafeber ${ }^{1}$
}

Address: ${ }^{1}$ Department of Paediatrics, Division of Neonatology, VU University Medical Center, Amsterdam, The Netherlands and ${ }^{2}$ Institute of Research in Extramural Medicine, VU University Medical Center, Amsterdam, The Netherlands

Email: Elisabeth AM Westerbeek - e.westerbeek@vumc.nl; Ruurd M van Elburg* - rm.vanelburg@vumc.nl; Anemone van den Berg - a.vandenberg@vumc.nl; Jolice van den Berg - jolicevandenberg@hotmail.com; Jos WR Twisk - jwr.twisk@vumc.nl; Willem PF Fetter - w.fetter@vumc.nl; Harrie N Lafeber - hn.lafeber@vumc.nl

* Corresponding author

Published: 23 October 2008

BMC Pediatrics 2008, 8:46 doi:10.1 |86/147|-2431-8-46
Received: I August 2008

Accepted: 23 October 2008

This article is available from: http://www.biomedcentral.com/I47I-243I/8/46

(C) 2008 Westerbeek et al; licensee BioMed Central Ltd.

This is an Open Access article distributed under the terms of the Creative Commons Attribution License (http://creativecommons.org/licenses/by/2.0), which permits unrestricted use, distribution, and reproduction in any medium, provided the original work is properly cited.

\begin{abstract}
Background: Prevention of serious infections in preterm infants is a challenge, since prematurity and low birth weight often requires many interventions and high utility of devices. Furthermore, the possibility to administer enteral nutrition is limited due to immaturity of the gastrointestinal tract in the presence of a developing immune system. In combination with delayed intestinal bacterial colonisation compared with term infants, this may increase the risk for serious infections. Acidic and neutral oligosaccharides play an important role in the development of the immune system, intestinal bacterial colonisation and functional integrity of the gut. This trial aims to determine the effect of enteral supplementation of acidic and neutral oligosaccharides on infectious morbidity (primary outcome), immune response to immunizations, feeding tolerance and short-term and long-term outcome in preterm infants. In addition, an attempt is made to elucidate the role of acidic and neutral oligosaccharides in postnatal modulation of the immune response and postnatal adaptation of the gut.
\end{abstract}

Methods/Design: In a double-blind placebo controlled randomised trial, 120 preterm infants (gestational age $<32$ weeks and/ or birth weight $<1500$ gram) are randomly allocated to receive enteral acidic and neutral oligosaccharides supplementation $(20 \% / 80 \%)$ or placebo supplementation (maltodextrin) between day 3 and 30 of life. Primary outcome is infectious morbidity (defined as the incidence of serious infections). The role of acidic and neutral oligosaccharides in modulation of the immune response is investigated by determining the immune response to DTaP-IPV-Hib(-HBV)+PCV7 immunizations, plasma cytokine concentrations, faecal Calprotectin and IL-8. The effect of enteral acidic and neutral oligosaccharides supplementation on postnatal adaptation of the gut is investigated by measuring feeding tolerance, intestinal permeability, intestinal viscosity, and determining intestinal microflora. Furthermore, short-term and long-term outcome are evaluated.

Discussion: Especially preterm infants, who are at increased risk for serious infections, may benefit from supplementation of prebiotics. Most studies with prebiotics only focus on the colonisation of the intestinal microflora. However, the pathways how prebiotics may influence the immune system are not yet fully understood. Studying the immune modulatory effects is complex because of the multicausal risk of infections in preterm infants. The combination of neutral oligosaccharides with acidic oligosaccharides may have an increased beneficial effect on the immune system. Increased insight in the effects of prebiotics on the developing immune system may help to decrease the (infectious) morbidity and mortality in preterm infants.

Trial registration: Current Controlled Trials ISRCTNI62II826. 


\section{Background}

Preterm infants are at increased risk for the development of serious nosocomial infections, especially very low birth weight infants at a NICU [1]. In a recent review of the literature, we found that the intestinal bacterial colonisation in preterm infants is much more diverse than in term infants and that antibiotics cause a significant delay in the intestinal bacterial colonisation [2]. Furthermore, the possibility to administer enteral nutrition is limited due to immaturity of the gastrointestinal tract in the presence of a developing immune system.

Human milk has anti-inflammatory effects and bifidogenic effects on the intestinal microflora $[3,4]$. Term breastfed infants have less infections and develop less atopy compared with formula fed infants $[5,6]$. Many factors have been implicated in this effect, including human milk oligosaccharides [7,8]. Many attempts have been made to mimic this effect of human milk. Addition of prebiotics, consisting of neutral oligosaccharides, to infant formula has been found to show potential advantageous effects in term and preterm infants $[9,10]$. Besides neutral oligosaccharides, breast milk also contains acidic oligosaccharides [8]. In the past, research has mainly focussed on neutral oligosaccharides such as galacto-oligosaccharides and fructo-oligosaccharides (GOS/FOS). Supplementation of GOS/FOS in term and preterm infants results in: 1 . Stimulation of a bifidogenic intestinal flora $[11,12]$; 2 . Reduction of pathogens in the intestine [12]; 3. Production of beneficial fermentation metabolites such as short chain fatty acids (SCFA) [10]; 4. Decrease of stool pH [13]; 5. Improved intestinal physiology (stool characteristics, motility) [14]; 6. Less infections and atopy $[15,16]$.

In breast milk $80 \%$ of the oligosaccharides are neutral (as in GOS/FOS), and 20\% are acidic. Acidic oligosaccharides (AOS) can be derived from carrots with their active component pectin. Pectin is a common structural component of all higher plants. Cooking of pectin-containing vegetables induces the cleavage of the long-chain pectin polymers into acidic oligosaccharides. For already nearly 100 years, carrots are known to have health promoting effects. In 1908, carrot soup was used as treatment of diarrhoea [17]. In 1997, Guggenbichler identified the anti-adhesive effect of acidic oligosaccharides [18].

The combination of acidic and neutral oligosaccharides may have several advantageous effects [10,19-21]: 1 . Improvement of the response to immunizations; 2 . Stimulation of Th1 cytokine response (e.g. TNF- $\alpha$, IFNgamma) and decreasing the Th2 cytokine release (e.g. IL10, IL-4, IL-5); 3. Stimulation of a bifidogenic intestinal flora; 4. Preventing adhesion of pathogens to epithelial tissues.
As a result of these effects, we hypothesise that preterm infants receiving a combination of GOS/FOS with AOS may have: 1 . Less infections; 2 . Better response to immunizations; 3 . Less atopy later in life; 4 . Less feeding intolerance.

As infections are still a major cause of morbidity and mortality in preterm infants, reducing the incidence of serious infections is very important. Controversy exists on the definitions for serious infections in neonates. Therefore in a previous study, we adjusted the criteria of the Centers for Disease Control and Prevention for serious infections in children $<1$ year for use in neonates [1], and found in a prospective study these criteria applicable in preterm infants [22].

In conclusion, this double-blind randomised controlled trial aims to determine the effect of enteral supplementation of acidic and neutral oligosaccharides on infectious morbidity (primary outcome), immune response to immunizations, feeding tolerance and short-term and long-term outcome in preterm infants. In addition, an attempt is made to elucidate the role of acidic and neutral oligosaccharides in postnatal modulation of the immune response and postnatal adaptation of the gut.

\section{Methods/Design}

The study is designed as a double-blind placebo controlled randomised clinical trial. Approval of the study protocol by the medical ethical review board of VU University Medical Center Amsterdam is obtained before the start of the study.

\section{Study population}

Infants with a gestational age $<32$ weeks and/or birth weight $<1500$ gram admitted to the level III neonatal intensive care unit (NICU) of the VU University Medical Center, Amsterdam, are eligible for participation in the study. Written informed consent is obtained from all parents.

Exclusion criteria are: major congenital or chromosomal anomalies, death $<48$ hours after birth, transfer to another hospital $<48$ hours after birth and admission from an extra regional hospital.

\section{Treatment allocation and blinding}

To balance birth weight distribution into treatment groups, each infant is stratified to one of three birth weight groups ( $\leq 799 \mathrm{~g}, 800-1199 \mathrm{~g}, \geq 1200 \mathrm{~g})$ and randomly allocated to treatment within 48 hours after birth. An independent researcher uses a computer-generated randomisation table (provided by Danone Research, Friedrichsdorf, Germany) to assign infants to treatment $\mathrm{N}$ or O. Investigators, parents, medical and nursing staff are 
unaware of treatment allocation. The randomisation code is broken after data analysis is performed.

\section{Treatment}

Acidic and neutral oligosaccharides powder and the placebo powder (maltodextrin) are prepared by Danone Research, Friedrichsdorf, Germany and are packed sterile. During the study period, acidic and neutral oligosaccharides and placebo powder are monitored for stability and microbiological contamination.

Between days 3 and 30 of life, acidic and neutral oligosaccharides supplementation $(20 \% / 80 \%$ mixture) is administered in a dose of maximal $1.5 \mathrm{~g} / \mathrm{kg} /$ day to breast milk or preterm formula in the intervention group. Two members of the nursing staff daily add supplementation to breast milk or to preterm formula (Nenatal Start ${ }^{\varpi}$, Nutricia Nederland B.V., Zoetermeer, The Netherlands), according to the parents' choice. Per $100 \mathrm{~mL}$, Nenatal Start ${ }^{\oplus}$ provides 80 kcal, $2.4 \mathrm{~g}$ protein (casein-whey protein ratio 40:60), 4.4 $\mathrm{g}$ fat, and $7.8 \mathrm{~g}$ carbohydrate. When infants are transferred to another hospital before the end of the study, the protocol is continued under supervision of the principal investigator $(\mathrm{EW})$.

\section{Nutritional support}

Protocol guidelines for the introduction of parenteral and enteral nutrition follow current practice at our NICU. Nutritional support is administered as previously described [23].
For each infant in the study, a feeding schedule is proposed based on birth weight and the guidelines as mentioned above. However, the medical staff of our NICU has final responsibility for the administration of parenteral nutrition and advancement of enteral nutrition.

After discharge all infants receive breast milk or preterm formula Nenatal Start (without GOS/FOS) ${ }^{\varpi}$ until term, and Nenatal 1 (without GOS/FOS) ${ }^{\circledast}$ until the corrected age of 6 months.

\section{Study outcome measures}

Clinical outcome measures

Primary outcome of the study is the effect of acidic and neutral oligosaccharides $(20 \% / 80 \%$ mixture) supplemented to the enteral nutrition on infectious morbidity as previously defined $[1,22]$. The occurrence of serious infections is determined by two investigators, unaware of treatment allocation, as previously described $[1,22]$.

The following perinatal characteristics are registered to assess prognostic similarity: maternal age and race, obstetric diagnosis, administration of antenatal steroids and antibiotics, mode of delivery, sex, gestational age, birth weight, birth weight $<10^{\text {th }}$ percentile [24], Apgar scores, $\mathrm{pH}$ of the umbilical artery, clinical risk index for babies [25], and administration of surfactant.

During the study period, actual intake of enteral and parenteral nutrition, powder supplementation and type of feeding (breast milk or preterm formula) are recorded

Table I: Clinical outcome measures

\begin{tabular}{|c|c|}
\hline & Remarks \\
\hline \multicolumn{2}{|l|}{ Infectious morbidity } \\
\hline Serious infections & Primary outcome \\
\hline \multicolumn{2}{|l|}{ Number of infectious episodes } \\
\hline \multicolumn{2}{|l|}{ Cultured micro-organisms } \\
\hline \multicolumn{2}{|l|}{ Feeding tolerance } \\
\hline \multicolumn{2}{|l|}{ Enteral feeding $>120 \mathrm{~mL} / \mathrm{kg} /$ day } \\
\hline \multicolumn{2}{|l|}{ Age at finishing parenteral nutrition } \\
\hline Necrotising enterocolitis & Bell et al.[35] \\
\hline \multicolumn{2}{|l|}{ Short-term outcome } \\
\hline Weight $z$ scores at birth, day 30 and at discharge & Usher et al. [24] \\
\hline \multicolumn{2}{|l|}{ Patent ductus arteriosus } \\
\hline \multicolumn{2}{|l|}{ Ventilatory support } \\
\hline Use of oxygen at postmenstrual age of 36 weeks & Jobe et al. [36] \\
\hline Intraventricular hemorrhage & Papile et al. [37] \\
\hline Retinopathy of prematurity & Committee for ROP. [38] \\
\hline \multicolumn{2}{|l|}{ Death } \\
\hline Age at discharge from NICU and age at discharge home & \\
\hline
\end{tabular}

ROP = retinopathy of prematurity; NICU = neonatal intensive care unite. 
daily. Feeding tolerance and short-term outcome are evaluated. (Table 1)

\section{Immune response}

The effect of acidic and neutral oligosaccharides supplemented enteral nutrition on the immune response is investigated, in collaboration with the National Institute for Public Health and Environment, by determining the development of the immune response to DTaP-IPV-Hib(HBV) + PCV7 immunizations (after the first 3 doses), and the development of the memory function of the immune response to these immunizations by measuring the response after the $4^{\text {th }}$ booster dose. In addition, the plasma cytokine concentrations (Il-2, Il-4, IL-5, Il-8, IL-10, TGF, IFN), faecal Calprotectin measured by ELISA (Buhlmann, Switzerland), and IL8 measured by random-access chemiluminescence immunoassay (Siemens, The Netherlands) are determined.

\section{Postnatal adaptation of the gut}

The effect of acidic and neutral oligosaccharides supplemented enteral nutrition on postnatal adaptation of the gut is studied by measuring feeding tolerance, intestinal permeability, intestinal microflora and intestinal viscosity.

Intestinal permeability is measured by the sugar absorption test [26]. After instillation of the test solution, $2 \mathrm{~mL} /$ $\mathrm{kg}$ by nasogastric tube, urine is collected for 6 hours. After collection, $0.1 \mathrm{~mL}$ chlorohexidine digluconate $20 \%$ (preservative) is added to the urine and samples are stored at $-20^{\circ} \mathrm{C}$ until analysis. Lactulose and mannitol concentrations ( $\mathrm{mmol} / \mathrm{mol}$ creatinine) are measured by gas chromatography as previously described [27]. The lactulose/ mannitol ratio is calculated and used as a measure of intestinal permeability.

Faecal samples are stored at $-20^{\circ} \mathrm{C}$ until analysis by fluorescent in situ hybridisation (FISH) using specific $16 \mathrm{~S}$ rDNA-targeted [28]. Intestinal viscosity is measured by high-pressure capillary rheometry (viscosimetry) as described by Mihatsch et al. [14].

\section{Long-term outcome}

To determine the incidence of allergic and infectious disease in the first year of life standardized questionnaires will be sent to the parents prior to the follow-up visit at the corrected age of 1 year [29]. Faecal samples (FISH, Calprotectin and IL-8) and IgE/IgG4 levels in blood will be measured at the age of 5 and 12 months.

To investigate neurodevelopmental outcome, neurological status, vision, hearing and Mental Development Index (MDI) and Psychomotor Development Index (PDI) of the Bayley Scales of Infant Development II (BSID-II) at the corrected age of 1 and 2 years (as part of the regular follow-up of NICU infants) are assessed [30,31].

To determine the frequency of side-effects after the first 4 immunizations, standardized questionnaires will be given to the parents at the time of immunizations. (Table 2)

\section{Sample size}

Based on the differences in incidences in infectious morbidity ( $76 \%$ and $50 \%$ respectively) in the GEEF study [22], and a two-tailed $\alpha=0.05, \beta=0.20$, a sample size of $2 \times[2 * 7.85 * 0.63(0,37)] /(0,26)^{2}=2 \times 54$ infants is calcu-

Table 2: Study Schedule

\begin{tabular}{|c|c|c|c|c|c|c|c|c|}
\hline & $<48 \mathrm{~h}$ & Day 4 & day 7 & day 14 & day 30 & 5 months & I year & 2 year \\
\hline \multicolumn{9}{|l|}{ Immune response } \\
\hline Response to immunizations & & & & & & $x$ & $x$ & \\
\hline Cytokine response & $x$ & & $x$ & $x$ & & $x$ & $x$ & \\
\hline Faecal Calprotectin/IL-8 & $x$ & & $x$ & $x$ & $x$ & $x$ & $x$ & \\
\hline \multicolumn{9}{|c|}{ Postnatal adaptation of the gut } \\
\hline Intestinal permeability & $x$ & $x$ & $x$ & & & & & \\
\hline Intestinal microflora & $x$ & & $x$ & $x$ & $x$ & $x$ & $x$ & \\
\hline Intestinal viscosity & & & & & $x$ & $x$ & $x$ & \\
\hline \multicolumn{9}{|l|}{ Long-term outcome } \\
\hline $\lg \mathrm{E} / \lg \mathrm{G} 4$ & $x$ & & & & & $x$ & $x$ & \\
\hline Allergic and infectious diseases & & & & & & & $x$ & \\
\hline \multicolumn{9}{|l|}{ Side effects immunizations ${ }^{\dagger}$} \\
\hline Neurodevelopment & & & & & & & $x$ & $x$ \\
\hline
\end{tabular}

†Standardized questionnaires (Preparedness and Response Unit, Centre for Infectious disease Control Netherlands, National Institute for Public Health and the Environment, The Netherlands) after the $1^{\text {st }}, 2^{\text {nd }}, 3^{\text {rd }}$ and $4^{\text {th }}$ immunization. 
lated. Based on an expected drop-out rate of $10 \%$ during the study period $2 \times 60$ infants will be included.

\section{Statistical analysis}

To determine whether randomisation is successful, prognostic similarity (perinatal and nutritional characteristics) between treatment groups is assessed. The Students' t-test, Mann-Whitney U test, and chi-square test or Fisher's exact test are used to compare continuous normally distributed, nonparametric continuous and dichotomous data respectively.

Logistic regression is performed to examine whether acidic and neutral oligosaccharide supplemented enteral nutrition decreases the incidence of serious infections. In an additional analysis, adjustments are made for possible confounding factors such as administration of antenatal corticosteroids, birth weight $<10$ th percentile and administration of breast milk. Analyses of secondary outcomes (only crude) is performed by Students' t- test, Mann-Whitney $U$ test, chi-square test or Fisher's exact test for (non)parametric continuous, dichotomous data and time-dependent data respectively.

Generalised estimated equations [32] are used to analyse differences and changes over time in plasma cytokine concentrations, faecal Calprotectin and IL-8, intestinal permeability, intestinal microflora and intestinal viscosity. Differences of optimal and non-optimal neuromotor development and normal and abnormal mental/motor development in oligosaccharides and control groups is examined by logistic regression with adjustments for possible confounding factors as gestational age and birth weight.

All statistical analyses are performed on an intention to treat basis. In addition, alternative per protocol analyses are performed, excluding all patients who are not treated according to protocol, defined as more than 3 consecutive days or a total of 5 days on minimal enteral feeding or without supplementation. For all statistic analyses a $\mathrm{p}$ value $<0.05$ is considered significant (two-tailed). SPSS 15.0 (SPSS Inc., Chicago, IL, USA) is used for data analysis.

\section{Discussion}

There is increasing evidence that prebiotics play an important role in the development of the intestinal microflora and the immune system, and may help to decrease the risk of infectious diseases. Especially preterm infants, who are at increased risk for serious infections, may benefit from supplementation of prebiotics. Most studies with prebiotics only focus on the colonisation of the intestinal microflora. The influence on the immune system is not yet fully understood [33]. Studying the immune modulatory effects is complex because of the multicausal risk of infections in preterm infants [34]. The combination of neutral oligosaccharides with acidic oligosaccharides may have an increased beneficial effect on the immune system of preterm infants due to the specific conditions in the luminal part of the developing gut wall. Not only the immune effects, such as morbidity due to infections and response to immunizations will be investigated, but also other signs and symptoms such as feeding tolerance, short-term, long-term and postnatal adaptation of the gut (intestinal microflora, intestinal permeability, intestinal viscosity). Increased insight in the effects of prebiotics on the developing immune system may help to find ways to decrease the (infectious) morbidity and mortality in preterm infants.

\section{Competing interests}

Danone Research (Friedrichsdorf, Germany) for the financial support and for providing Nenatal Start ${ }^{\circledast}$, Nenatal $1^{\oplus}$, acidic and neutral oligosaccharides and placebo supplementation.

\section{Authors' contributions}

Ruurd M van Elburg, Elisabeth AM Westerbeek and Harrie $\mathrm{N}$ Lafeber formulated the research question and wrote the study protocol. Anemone van den Berg, Willem P Fetter and Jolice van den Berg contributed to the development of the protocol. Jos WR Twisk gave advice on statistical analysis. Elisabeth AM Westerbeek and Ruurd M van Elburg wrote the draft for this manuscript and the other authors reviewed the manuscript. All authors approved the final version of the manuscript.

\section{Acknowledgements}

We would like to acknowledge Edward ES Nieuwenhuis, Fiona RM van der Klis and Guy AM Berbers for their contribution to the study design.

\section{References}

I. van der Zwet WC, Kaiser AM, van Elburg RM, Fetter WPF, Vandenbroucke-Grauls CMJE: Nosocomial infections in a Dutch neonatal intensive care unit: surveillance study with definitions for infection specifically adapted for neonates. J Hosp Infect 2005, 6 I:300-3 II.

2. Westerbeek EAM, van den Berg A, Lafeber HN, Knol J, Fetter WPF, van Elburg RM: The intestinal bacterial colonisation in preterm infants: A review of the literature. Clin Nutr 2006, 25:36I-368.

3. Harmsen HJ, Wildeboer-Veloo AC, Raangs GC, Wagendorp AA, Klijn N, Bindels JG, Welling GW: Analysis of intestinal flora development in breast-fed and formula-fed infants by using identification and detection methods. J Pediatr Gastroenterol Nutr 2000, 30:61-67.

4. Yoshioka H, Iseki K, Fuijta K: Development and differences of intestinal flora in the neonatal period in vreast-fed and bottle-fed infants. Pediatrics 1983, 72:317-321.

5. Holt PG, Sly PD, Bjorksten B: Atopic versus infectious diseases in childhood: a question of balance? Pediatr Allergy Immunol 1997 , 8:53-58.

6. Kull I, Wickman M, Lilja G, Nordvall SL, Pershagen G: Breast feeding and allergic diseases in infants-a prospective birth cohort study. Arch Dis Child 2002, 87:478-48I. 
7. Bode L: Recent advances on structure, metabolism and function of human milk oligosaccharides. J Nutr 2006, I36:2127-2130.

8. Boehm G, Stahl B: Oligosaccharides. Functional Dairy Products. Edited by: Mattila-Sandholm T. Cambridge: Woodhead; 2002:203-243.

9. Fanaro S, Boehm G, Garssen J, Knol J, Mosca F, Stahl B, Vigi V: Galacto-oligosaccharides and long-chain fructo-oligosaccharides as prebiotics in infant formulas: a review. Acta Paediatr Suppl 2005, 94:22-26.

10. Boehm G, Jelinek J, Stahl B, van Laere K, Knol J, Fanaro S, Moro G, Vigi V: Prebiotics in infant formulas. J Clin Gastroenterol 2004 38:S76-79.

II. Boehm G, Lidestri M, Casetta P, Jelinek J, Negretti F, Stahl B, Marini A: Supplementation of a bovine milk formula with an oligosaccharide mixture increases counts of faecal bifidobacteria in preterm infants. Arch Dis Child Fetal Neonatal Ed 2002, 86:FI78-|8I.

12. Knol J, Boehm G, Lidestri M, Negretti F, Jelinek J, Agosti M, Stahl B, Marini A, Mosca F: Increase of faecal bifidobacteria due to dietary oligosaccharides induces a reduction of clinically relevant pathogen germs in the faeces of formula-fed preterm infants. Acta Paediatr 2005, 94:31-33.

13. Knol J, Scholtens P, Kafta C, Steenbakkers J, Groß, Helm K, Klarczyk $M$, Schöpfer $\mathrm{H}$, Böckler H-M, Wells J: Colon microflora in infants fed formula with galacto- and fructo-oligosaccharides: more like breast-fed infants. J Pediatr Gastroenterol Nutr 2005, 40:36-42.

14. Mihatsch WA, Högel J, Pohlandt F: Hydrolyzed protein accelerates the gastro-intestinal transport of formula in preterm infants. Acta Paediatr 2001, 90:196-198.

15. Arslanoglu S, Moro GE, Boehm G: Early supplementation of prebiotic oligosaccharides protects formula-fed infants against infections during the first 6 months of life. J Nutr 2007 I 37:2420-2424.

16. Arslanoglu S, Moro GE, Schmitt J, Tandoi L, Rizzardi S, Boehm G: Early dietary intervention with a mixture of prebiotic oligosaccharides reduces the incidence of allergic manifestations and infections during the first two years of life. J Nutr 2008, 3015:1091-1095.

17. Moro E: Karottensuppe bei ernährungsstörungen der säuglinge. München Med Wschr 1908, 3 I: I637-I640.

18. Guggenbichler JP, De Bettignies-Dutz A, Meissner P, Schellmoser S Jurentsch J: Acidic oligosaccharides from natural sources block adherence of Escherichia coli on uroepithelial cells. Pharm Pharmacol Lett 1997, 7:35-38.

19. Fanaro S, Jelinek J, Stahl B, Boehm G, Kock R, Vigi V: Acidic oligosaccharides from pectin hydrolysate as new component for infant formulae: Effect on intestinal flora stool characteristics and pH. J Pediatr Gastroenterol Nutr 2005, 4 I : I 86- I 90.

20. Kastner U, Glasl S, Follrich B, Guggenbichler, Jurenitsch J: Saure oligosaccharide als wirkprinzip von wäßrigen zubereitungen aus der karotte in der prophylaxe und therapie von gastrointestinalen infectionen. Wiener Med Wschr 2002, I 52:379-38I.

21. Lee J, Shim JS, Lee JS, Kim M, Chung M, Kim KH: Pectin-like acidic oligosaccharide from Panax ginseng with selective antiadhesive activity against pathogenic bacteria. Carbohydrate Research 2006, 34I: I| I54-II63.

22. van den Berg A, van Elburg RM, Westerbeek EAM, Twisk JWR, Fetter WPF: Glutamine-enriched enteral nutrition in very-lowbirth-weight infants and effects on feeding tolerance and infectious morbidity: a randomized controlled trial. Am J Clin Nutr 2005, 81:1397-|404.

23. van den Berg A, van Elburg RM, Twisk JWR, Fetter WPF: Glutamine-enriched enteral nutrition in very low birth weight infants. Design of a double-blind randomised controlled trial. BMC Pediatr 2004, 4: I7.

24. Usher R, McLean F: Intrauterine growth of live-born Caucasian infants at sea level: standards obtained from measurements in 7 dimensions of infants born between 25 and 44 weeks of gestation. J Pediatr 1969, 74:901-910.

25. The CRIB (clinical risk index for babies) score: a tool for assessing initial neonatal risk and comparing performance of neonatal intensive care units. The International Neonatal Network. Lancet 1993, 342:193-198.
26. van Elburg RM, Fetter WP, Bunkers CM, Heymans HS: Intestinal permeability in relation to birth weight and gestational and postnatal age. Arch Dis Child Fetal Neonatal Ed 2003, 88:F52-F55.

27. van Elburg RM, Uil J], Kokke FT, Mulder AM, van de Broek WG, Mulder CJ, Heymans HS: Repeatability of the sugar-absorption test, using lactulose and mannitol, for measuring intestinal permeability for sugars. I Pediatr Gastroenterol Nutr 1995, 20: $184-188$

28. Harmsen HJ, Wildeboer-Veloo AC, Raangs GC, Wagendorp AA Klijn N, Bindels JG, Welling WG: Analysis of intestinal flora development in breast-fed and formula-fed infants using molecular identification and detection methods. J Pediatr Gasteroenterol Nutr 2000, 30:6 I-67

29. van den Berg A, van Zwol A, Moll HA, Fetter WPF, van Elburg RM: Glutamine-enriched enteral nutrition in VLBW infants: effect on the incidence of allergic and infectious diseases in the first year of life. Arch Pediatr Adolesc Med 2007, I 6 I : I 095- I I 0 I.

30. Samsom JF, de Groot L: The influence of postural control on motility and hand function in a group of 'high risk' preterm infants at I year of age. Early Hum Dev 2000, 60:101-II3.

31. Bayley N: Bayley Scales of Infant development II. The Psychological Corporation. New York 2nd edition. 1993.

32. Twisk JWR: Applied longitudinal data analysis for epidemiology. A practical guide Cambridge UK: Cambridge University Press; 2003.

33. Boehm G, Moro G: Structural and functional aspects of prebiotics used in infant nutrition. I Nutr 2008, I38:1818S-1828S

34. Lafeber HN, Westerbeek EAM, van den Berg A, Fetter WPF, van Elburg RM: Nutritional factors influencing infections in preterm infants. J Nutr 2008, 138:1813S-1817S.

35. Bell MJ, Ternberg JL, Feigin RD, Keating JP, Marshall R, Barton L, Brotherton T: Neonatal necrotizing enterocolitis. Therapeutic decisions based upon clinical staging. Ann Surg 1978, 187:1-7.

36. Jobe $\mathrm{AH}$, Bancalari E: Bronchopulmonary dyplasia. Am J Respir Crit Care Med 200I, I63:I723-I729.

37. Papile LA, Burstein J, Burstein R, Koffler H: Incidence and evolution of subependymal and intraventricular hemorrhage: a study of infants with birth weights less than I,500 gm. J Pediatr 1978, 92:529-534.

38. An international classification of retinopathy of prematurity. The committee for the Classification of Retinopathy of Prematurity. Arch Ophthalmol 1984, I02: I I30-II34.

\section{Pre-publication history}

The pre-publication history for this paper can be accessed here:

http://www.biomedcentral.com/1471-2431/8/46/prepub

Publish with Bio Med Central and every scientist can read your work free of charge

"BioMed Central will be the most significant development for disseminating the results of biomedical research in our lifetime. "

Sir Paul Nurse, Cancer Research UK

Your research papers will be:

- available free of charge to the entire biomedical community

- peer reviewed and published immediately upon acceptance

- cited in PubMed and archived on PubMed Central

- yours - you keep the copyright 